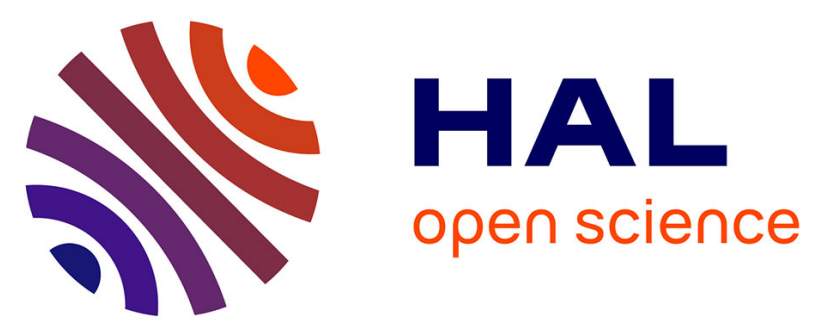

\title{
Infiltration of Molten Silicon in a Porous Body of B4C Under Microwave Heating
}

Mathieu Dutto, Dominique Goeuriot, Sébastien Saunier, Sergio Sao-Joao, Matthieu Lenci, Sylvain Marinel, Shmuel Hayun, Nachum Frage

\section{To cite this version:}

Mathieu Dutto, Dominique Goeuriot, Sébastien Saunier, Sergio Sao-Joao, Matthieu Lenci, et al.. Infiltration of Molten Silicon in a Porous Body of B4C Under Microwave Heating. Ceramic Transactions, 2018, Advances in High Temperature Ceramic Matrix Compo sites and Materials for Sustainable Development;, 263, pp.157-165. 10.1002/9781119407270.ch16 . emse-02016461

\section{HAL Id: emse-02016461 \\ https://hal-emse.ccsd.cnrs.fr/emse-02016461}

Submitted on 23 Aug 2021

HAL is a multi-disciplinary open access archive for the deposit and dissemination of scientific research documents, whether they are published or not. The documents may come from teaching and research institutions in France or abroad, or from public or private research centers.
L'archive ouverte pluridisciplinaire HAL, est destinée au dépôt et à la diffusion de documents scientifiques de niveau recherche, publiés ou non, émanant des établissements d'enseignement et de recherche français ou étrangers, des laboratoires publics ou privés. 


\title{
INFILTRATION OF MOLTEN SILICON IN A POROUS BODY OF B $\mathrm{B}_{4} \mathrm{C}$ UNDER MICROWAVE HEATING
}

\author{
Mathieu Dutto ${ }^{1,3}$, Dominique Goeuriot ${ }^{1}$, Sébastien Saunier ${ }^{1}$,Sergio Sao-Joao ${ }^{1}$, Matthieu \\ Lenci $^{1}$, Sylvain Marinel ${ }^{2}$,Shmuel Hayun ${ }^{3}$, Nachum Frage ${ }^{3}$ \\ ${ }^{1}$ Laboratoire Georges Friedel UMR 5307, Centre des Science des Matériaux et des \\ Structures, Mines Saint-Etienne, 42023 Saint-Etienne Cedex 2, France \\ ${ }^{2}$ CRISMAT Laboratory UMR 6508 CNRS-ENSICaen-UCBN, 6 Boulevard du Maréchal \\ Juin, 14050 Caen Cedex, France \\ ${ }^{3}$ Department of Materials Engineering, Ben-Gurion University of Negev, P.O. Box 653, \\ Beer-Sheva 84105, Israel
}

\section{ABSTRACT}

Boron Carbide is an attractive material for various applications that require high hardness and neutron absorption. Fully dense boron carbide bodies are usually fabricated using hot pressing at temperatures above $2000{ }^{\circ} \mathrm{C}$. Therefore, the production cost is very high, that constitutes the major drawback for widespread applications in the fields of defense and nuclear energy. An alternative route to decrease the production costs is the reactionbonded technique (RBBC). In this latter, a preform of porous $\mathrm{B}_{4} \mathrm{C}$ is obtained by compaction and partial densification. Then the material is infiltrated by molten metal or alloy. The metal can react with residual carbon and boron carbide to form carbide. This technique was extensively studied using conventional furnace but the use of microwave as a source of heating, as not used for this purpose so far, or only in a very few attempts. In the present study, the microstructure and mechanical properties of reaction bonding $\mathrm{B}_{4} \mathrm{C}$ infiltrated by silicon using microwave $(2.45 \mathrm{GHz})$ heating will be presented. The results will be discussed in the light of conventional RBBC.

\section{INTRODUCTION}

Light ceramics are particularly attractive for personal, land and airborne vehicle armor. It is admitted by common consensus that a high ballistic resistance is linked with a high hardness. Boron carbide which is the third harder material nowadays known (42GPa) [1, 2] and very low density $\left(2.52 \mathrm{~g} / \mathrm{cm}^{3}\right)$, is naturally studied to be used in ballistic protection devices. However their difficulties of production (hot pressing) and production cost are major drawbacks of the extended on boron carbide based armor. An alternative way for the fabrication of boron carbide based armor is to produce a composite of boron carbide and silicon carbide. This composite can be obtained by reaction between melted silicon and boron carbide, this method is called "reaction bonded" process [3, 4]. This method consists in infiltration by molten silicon of a porous green body of boron carbide (called preform) with or without addition of free carbon. The reaction of melted silicon with boron carbide or with free carbon leads to the formation of silicon carbide in the composite. The final composite consists in initial boron carbide grains, newly formed $\mathrm{B}_{12}(\mathrm{~B}, \mathrm{C}, \mathrm{Si})_{3}$ phase [5], silicon carbide and some unreacted residual silicon. The softer phase is the residual silicon, so to harden the composite it is right to decrease the amount of residual silicon in the final composite. One approach to achieve this goal is to reduce the pre-infiltration porosity of the boron carbide preform; it is common to pre-sintered boron carbide [6]. This approach is fully described in different publications [2,6-11], it was established that $\mathrm{SiC}$ phase depends on the carbon source (boron carbide or free carbon). In composite fabricated with free carbon SiC phase appears with a plate-like morphology, while the fabrication of the composite without free carbon leads to SiC with polygonal shape. In addition, boron carbide particles display a corerim structure and the rim regions, the composition of which correspond to the ternary 
$\mathrm{B}_{12}(\mathrm{~B}, \mathrm{C}, \mathrm{Si})_{3}[12]$, interconnect to a large extent the boron carbide particles. The mechanism of the rim-core structure formation has been discussed by Hayun et al [12] and it was attributed to a dissolution-precipitation process in the boron carbide-silicon system.

Most of the previous works were conducted in conventional furnace, only in few studies the use of microwave furnace [13-15] to heat up boron carbide and silicon can be found. Microwaves heating could conduct in preferential heating material that leads to a thermal gradient between two materials in contact and so microstructure different from those obtained by conventional heating. We propose in the present study to investigate the influence of the preform initial porosity and the dwell temperature on the macro/microstructure and hardness of the final composite after heat treatment by microwaves process.

\section{EXPERIMENTAL PROCEDURE}

\section{Sample Fabrication}

Boron carbide (average size $1 \mu \mathrm{m}$, HC.Starck, Grade HS) powder was uniaxially compacted at $100 \mathrm{MPa}$ and sintered at 2000 and $2150^{\circ} \mathrm{C}$ for $30 \mathrm{~min}$ in order to obtain preforms with initial density of $67 \%$ and $75 \%$. The pre-sintering step was conduct in a furnace under $\mathrm{Ar}$ atmosphere, the heating rate was $10^{\circ} \mathrm{C} / \mathrm{min}$ with a minimum $8 \mathrm{~h}$ dwell at $200^{\circ} \mathrm{C}$ to remove any residuals of the lubricant used during the compaction.

Three types of preforms (60\% (green preform), 67\% and 75\% (pre-sintered preform) of theoretical density) were infiltrated with molten silicon.

The infiltration process was conduct as follow: A piece of silicon was placed on the top of the porous body. The amount of silicon was chosen in order to fill the porous body. Preforms were infiltrated with molten silicon in a micro-wave furnace at $1350-1550^{\circ} \mathrm{C}$ range temperature for $15 \mathrm{~min}$ with a heating rate of $10^{\circ} \mathrm{C} / \mathrm{min}$ for the design-of-experiment. The infiltration step was realized under $\mathrm{Ar} / \mathrm{H}_{2}(10 \%)$ atmosphere to avoid oxidation of silicon and the heating was realized in a multimode $(2.45 \mathrm{GHz}, 6 \mathrm{~kW})$ cavity with a net volume of $1 \mathrm{~L}$. An alumino-silicate made crucible was used for thermal insulation (figure 1). The thermal cycle is realized using the instrumentation developed by Daniel Zymelka [16]. Obtained composites are denoted as their initial density and dwell temperature.

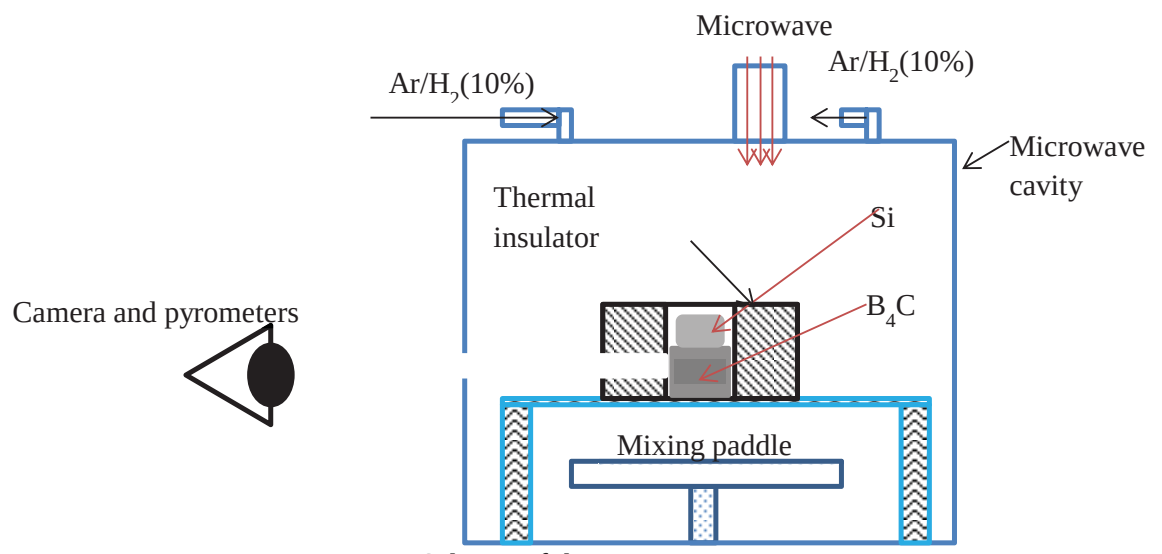

Figure 1: Scheme of the microwave cavity

The temperature was measured with pyrometers, one monochromatic (Ircon, Modeline 5) from 250 to $1000^{\circ} \mathrm{C}$ and one bichromatic (Ircon, Modline 5) from 700 to $1800^{\circ} \mathrm{C}$. Both of 
them were calibrated using the reference of silicon melting to found emissivity and e-slop of the system. The conventional error on the temperature measurement is $50^{\circ} \mathrm{C}$.

In order to verify the process conditions and our setup we infiltrated a $\mathrm{B}_{4} \mathrm{C}$ preform with $84 \%$ of the theoretical density using the thermal cycle reported in ref. [12] $1450{ }^{\circ} \mathrm{C}$ with $15 \mathrm{~min}$ of dwell time). From this preliminary test we found that:

1. The melting of silicon is possible by direct microwave heating, and a complete infiltration can be obtained at $1450^{\circ} \mathrm{C}-15 \mathrm{~min}$.

2. Using a CCD camera we found that a dwell time of $8 \mathrm{~min}$ at $1450-{ }^{\circ} \mathrm{C}$ is sufficient for complete the infiltration process, which represent a shorter time comparing to the conventional method. (Success infiltration is defined by the absence of visible residual silicon outside of the preform).

3. A large temperature difference was observed between the silicon and the boron carbide preform during the process: the temperature on boron carbide surface is $1280^{\circ} \mathrm{C}$ when silicon starts to melt $\left(1414^{\circ} \mathrm{C}\right)$. This fact could prove the microwave coupling of silicon just before and during its melting.

Based on these findings we design a two dimensional parametric study which allow modeling of the "answer", in this study hardness value, with a second degree polynomial model, on the two dimensions (dwell temperature and initial density) experimental domain. This modeling allows knowing optimum experimental conditions to obtain a high hardness for example. The experimental design chosen is a Doehlert one [17], that consists in three initial densities and five-dwell temperature combined like shown in figure (2).

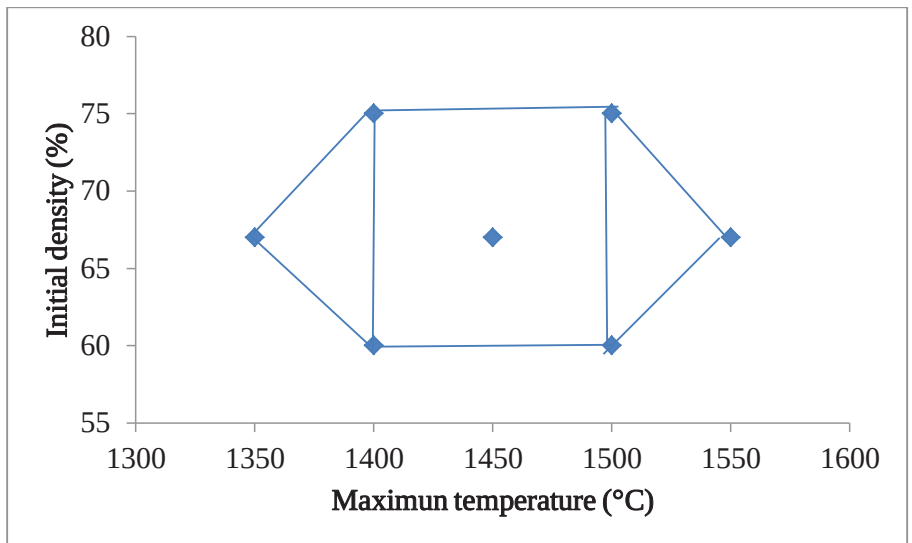

Figure 2: Design-of-experiment for this study. Doelhert plan with two axis (dwell temperature and initial porosity)

The weight percent of evaporated silicon during the infiltration process was calculated from the mass balance of the initial weight of the system (silicon plus boron carbide preform) and the final body as presented in the following equation:

$$
W_{\text {Variation }}=\frac{W_{\text {composite }}-\left(W_{S i}+W_{B_{4} C}\right)_{\text {initial }}}{\left(W_{S i}+W_{B_{4} C}\right)_{\text {initial }}} * 100
$$




\section{Microstructural Investigation}

The microstructure of the sample was studied by scanning electron microscopy (SEM) (MEB-FEG Jeol 6500F and MEB-FEG Zeiss supra 55 VP), coupled with an energy dispersive spectrometer (EDS) detector. The samples for SEM characterization were prepared using a standard metallographic procedure that included a last stage of polishing with $1 \mu \mathrm{m}$ diamond paste.

\section{Mechanical Property}

Hardness was measured by micro-indentation using a Microdurometer (Matsuzawa MxT70). The hardness measurement was performed on mounted samples for an easier observation of the imprints. Samples were covered with the same thickness of polymers so results can be compared. We used a Vickers device with $300 \mathrm{~g}$ load and $10 \mathrm{~s}$ of dwell time to limit cracks to the corners of imprint of hardness

\section{RESULT AND DISCUSSION}

\section{Microstructure of the infiltrated composites}

Typical microstructure of the infiltrated $\mathrm{B}_{4} \mathrm{C}$ composites (Fig. 3) consists of three phases, namely boron carbide, $\beta$-SiC and residual silicon. Using the EDS analyses the different phases can be assign. The $\beta$-SiC phase appears as light-gray plate-like particles. The lightergray regions correspond to residual $\mathrm{Si}$, and the dark gray areas are the boron carbide phase. The mechanism of the reaction between liquid $\mathrm{Si}$ and boron carbide has been discussed previously [11].

Differences between the microstructures obtained by conventional furnace and microwaves furnaces could result from temperature gradient between molten silicon (minimum $1414^{\circ} \mathrm{C}$ ) and boron carbide $\left(\approx 1300^{\circ} \mathrm{C}\right)$ at the first step of the infiltration.
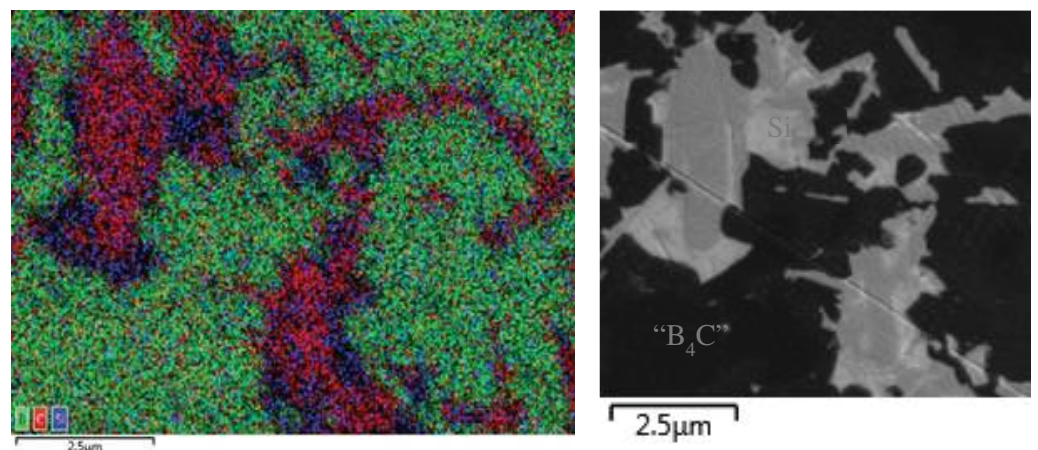

Figure 3: EDS analysis and SEM picture (secondary electron detector)

$\mathrm{SiC}$ (purple), $\mathrm{Si}$ (blue) and a boron rich phase : $\mathrm{B}_{4} \mathrm{C}$ and/or $\mathrm{B}_{12}$ (B,C,Si) 3 (green-yellow) 
The mass variation (i.e. amount of evaporated silicon) for all the experiments is presented in figure 4 .

The maximum mass variation is $-5 \%$. Microstructures (Fig. 5) of the infiltrated bodies show the presences of some residual porosity. Comparison of two samples with the same initial density shows a low decrease of the final porosity with the increase of the temperature. Increasing initial density seems to decrease the final porosity when the samples are presintered. From these findings, we can conclude that the use of $\mathrm{Ar} / 10 \% \mathrm{H}_{2}$ atmosphere may reduce the silicon evaporation.

Comparing these results to ones obtained in the conventional heat treatment, which often performed in vacuum, suggested that using microwave heating the consumption of silicon can be reduced by half and minimize the needs of additional cleaning steps of the infiltrated body.

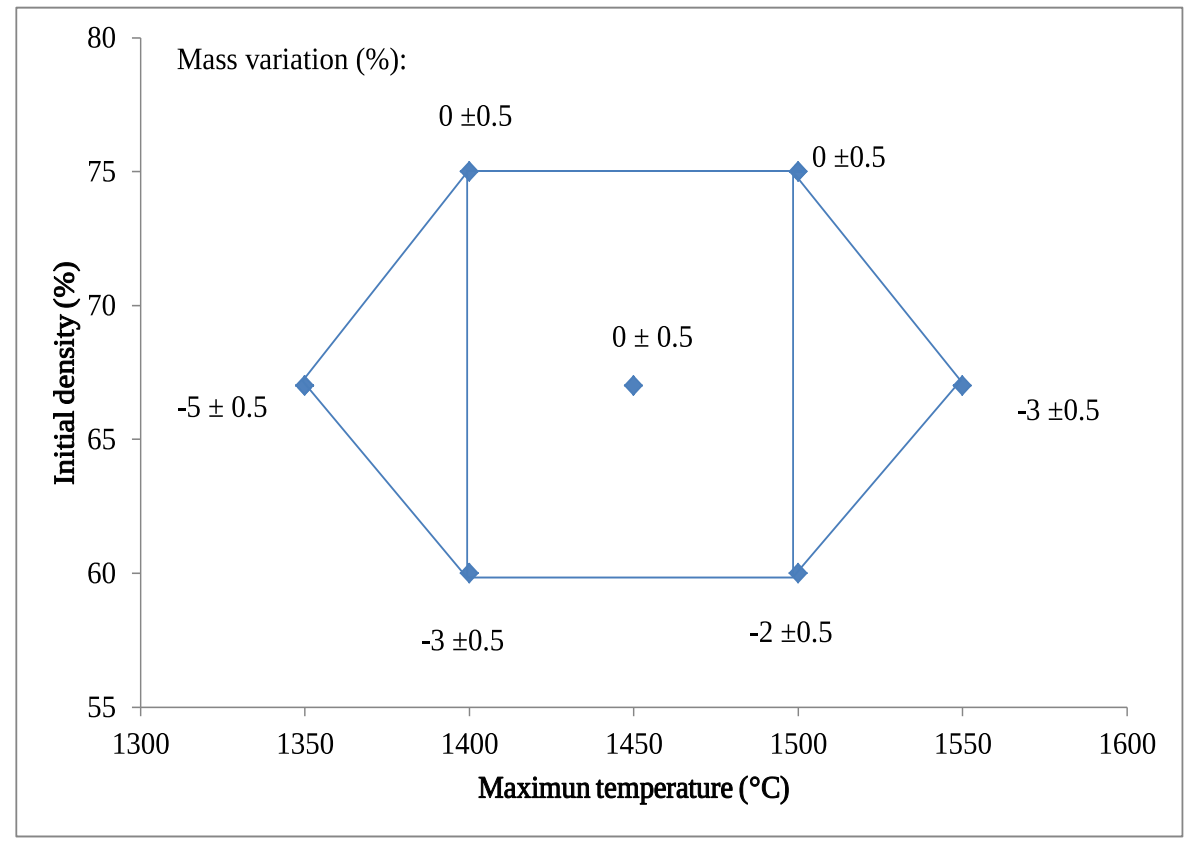

Figure 4: Mass variations on design-of-experiment 


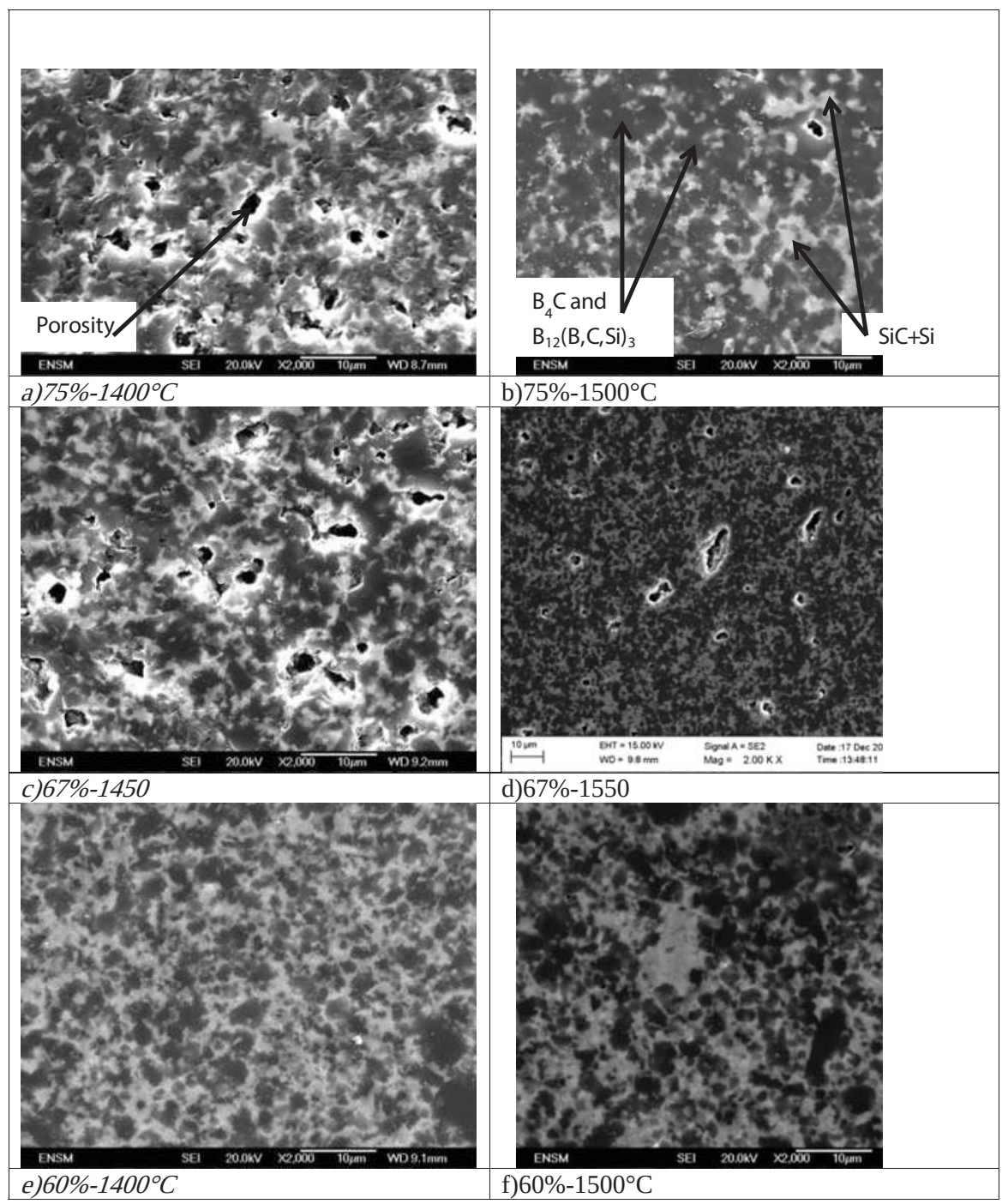

Figure 5: Microstructure (SEM image) of different composite. SEI and SE2 detector (Secondary electron detector). 
The hardness values (figure 6), measures increase with the decreasing of initial porosity. The obtained values found to be relatively high, in the range 2150-3140 $\mathrm{H}_{\mathrm{V} 300}$ despite the presence of residual silicon and porosity. On one hand it has to be noted that $\mathrm{SiC}$ hardness is lower than that of $\mathrm{B}_{4} \mathrm{C}$, on the other hand the replacement of $\mathrm{B}_{4} \mathrm{C}$ by $\mathrm{B}_{12}(\mathrm{~B}, \mathrm{C}, \mathrm{Si})_{3}$ isn't bad for the hardness, indeed according to the bibliography[2] $\mathrm{B}_{4} \mathrm{C}$ has a hardness of 42GPa and $\mathrm{B}_{12}(\mathrm{~B}, \mathrm{C}, \mathrm{Si})_{3} 46.1 \mathrm{GPa}$. In the present study we couldn't notice on any influence of the tretmant temperature on the hardness values. This finding is opposite to the results obtained in conventional method [18] where the influence of the infiltration temperature on the hardness values is strong. We used this data to modeling with Nemrodw software. According to the modeling (figure 7) the influence of the initial porosity found to be increasingly important when it is higher than $67 \%$ (the isohardness line getting closer). To optimize final hardness, $75 \%$ of initial density and $1400-1500^{\circ} \mathrm{C}$ of dwell temperature seem to be a good compromise.

According to the ref. [5] composite obtained with conventional heating present hardness of about $2300 \pm 300 \mathrm{H}_{\mathrm{V} 2000}$ which is lower than that obtained for sample treated in microwaves furnace.

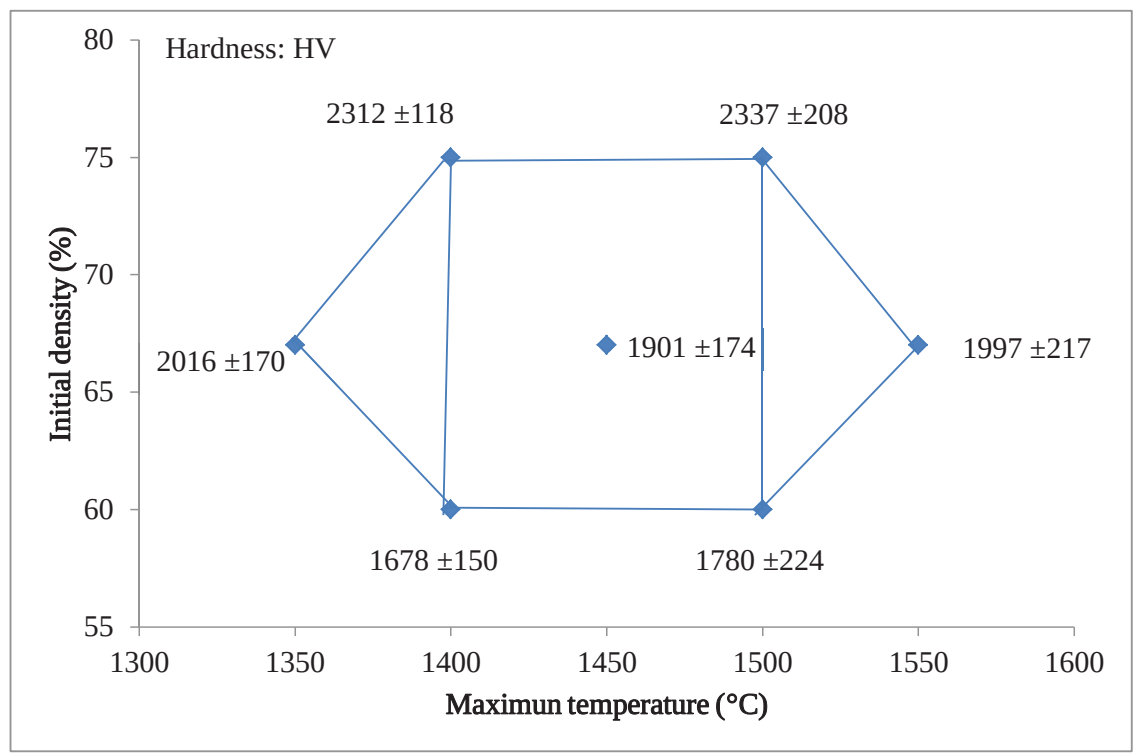

Figure 6: Hardness on design-of-experiment 


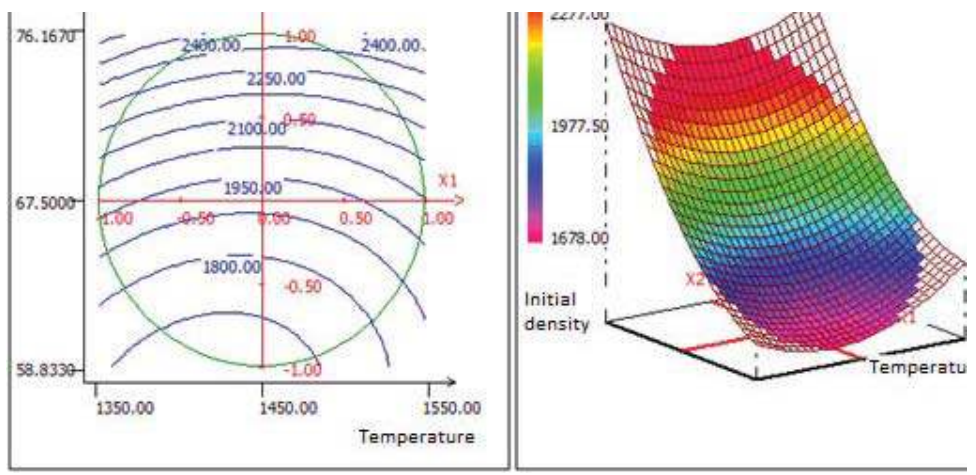

Figure 7: modeling of the influence of the initial porosity on the hardness. Left: 2D representation, blue lines are iso hardness. Right: 3D representation, X1 axis is temperature, $\mathrm{X} 2$ axis is initial density and last axis is composite hardness.

\section{CONCLUSION}

- The boron carbide reaction bonded method is adaptable to microwave furnace with $\mathrm{Ar} / \mathrm{H}_{2}$ atmosphere.

- The Hardness is strongly depended on the initial density and almost no dependency found on the infiltration temperature.

- The residual porosity is slightly influence by the dwell temperature and the initial density.

\section{ACKNOWLEDGEMENTS}

We wish to thank the Direction Général de l’Armement (DGA) France, and Israel Ministry of Defence (IMOD), for financial supports. Authors want to thank Dr. François Barthélemy, from the DGA and Dr. Udi Gallun, from IMOD, for the valuable support

\section{REFERENCES}

${ }^{1}$ F.Thévenot; « Boron Carbide A Comprehensive Review ». Journal of the European Ceramic Society, no 6 (1990): 20525.

${ }^{2}$ S.Hayun, H.Dilman, M.P.Dariel, N.frage; "The effect of carbon source on the microstructure and the mechanical properties of reaction bonded boron carbide”, ADVANCES IN SINTERING SCIENCE AND TECHNOLOGY , International Conference on Sintering, 209 (29-39) 2010

${ }^{3}$ M.K.Aghajanian, B.N.Morgan, J.R.Singh, J.Mears, R.A.Wolffe; “A New family of reaction bonded ceramics for armor applications"; pp.527-539 in ceramics Transactions, vol 134, Ceramic armor material by design edited by J.W.McCauley, A.Crowson, American Ceramic Society 2001

${ }^{4}$ K.M.Taylor, R.J.Palicke; “Dense carbide composite for armor and abrasives”. U.S. Pat. No.3765300, oct.16 1973 
${ }^{5}$ S.Hayun, A.Weizmann, M.P.Dariel, N.Frage; "The effect of particle size distribution on the microstructure and mechanical properties of boron carbide-based reaction-bonded composites”, Int. J. Appl. Ceram. Technol., 6[4] 492-500 (2009)

${ }^{6}$ S.Hayun, N.Frage, M.P.Dariel; "The morphology of ceramic phase in BxC-SiC-Si infiltrated composites”, J.Sol.St.Chem., 179(9), 2875-79 (2006)

${ }^{7}$ J.Wang, W.Lin, Z.Jiang, L.Duan, G.Yang;"The preparation and properties of SiCw/B4C composite infiltrated with molten Si”, Ceramic international 40 (2014) 6793-6798

${ }^{8}$ S.Tariolle, F.Thévenot, M.Aizenstein, M.P.Dariel, N.Frumin, N.Frage;"Boron carbideCopper infiltrated cermets”, Journal of solid state chemistry 177 (2004) 400-406

${ }^{9}$ N.Frage, L.Levin, N.Frumin, M.Gelbstein, M.P.Dariel; "Manufacturing B4C-(Al,Si) composite materials by metal alloy infiltration”, Journal of materials processing technology 143-144 (2003) 486-490

${ }^{10}$ H.Wu, S.Zhang, M.Gao, D.Zhu, Y.Pan, Y.Liu, H.Pan, F.J.Oliveira, J.M.Vieira; "Microstructure and mechanical properties of multi-carbide/(Al,Si) composite derived from porous B4C preforms by reactive melt infiltration”, Materials science and engineering A 551 (2012) 200-208

${ }^{11}$ S.Hayun, D.Rittel, N.Frage, M.P.Dariel; "Static and dynamic mechanical properties of infiltrated B4C-Si composite”, Materials science and engineering A 487 (2008) 405-409

${ }^{12}$ N.Frage, A.Weizmann, M.P.Dariel, N.Frage; "Microstructural evolution during the infiltration of boron carbide with molten silicon"; Journal of European ceramic society 30 (2010) 1007-1014

${ }^{13}$ A.Thuault, S.Marinel, E.Savary, R.Heuguet, S.Saunier, D.Goeuriot, D.Agrawal; "Processing of Reaction-Bonded B4C-SiC Composites in a Single-Mode Microwave Cavity”. Ceramics International 39, no 2 (mars 2013): 121519. doi:10.1016/j.ceramint.2012.07.047.

${ }^{14}$ P. G. Karandikar, D.Agrawal, J.Cheng; "Microwave assisted (MASS) processing of metalceramic and reaction-bonded composite",Ceramic Engineering and Science Proceedings Vol. 27, No. 2, 435-446 (2007) In Mechanical Properties and Performance of Engineering Ceramics and Composites II, Editor R. Tandon, American Ceramic Society

${ }^{15}$ A.Goldstein, R.Ruginets, L.Geifman; "Carbide matrix composites by fast MW reactionsintering in air of B4C-SiC-Al mixtures”, Ceramics International 35 (2009) 1297-1300

${ }^{16}$ D. Zymelka, S.Saunier, J.Molimard, D.Goeuriot,“ Contactless Monitoring of Shrinkage and Temperature Distribution during Hybrid Microwave Sintering”, Advanced Engineering Materials 13 [9] 901-905 (2011)

${ }^{17}$ M.Cissé, D.Montet, M.Tapia, G.Loiseau, M.Ducamp-Collin; "Influence of temperature and relative humidity on the immobilized lactoperoxidase system in a functional chitosan film", Food Hydrocolloids 28 361-366 (2012)

${ }^{18}$ C.Zhang, H.Ru, W.Wang, X.Yue, J.Zhao; “The role of the infiltration temperature in the reaction bonding of boron carbide by silicon infiltration”, Journal of American ceramic society 97 [10] 3286-3293 (2014) 